\title{
Can Breast Asymmetry Following the Treatment of Juvenile Idiopathic Scoliosis with Growing Rod Be Prevented? : A Preliminary Analysis
}

\author{
Yunus Atici, Barış Polat, ${ }^{2}$ Sinan Erdogan, ${ }^{3}$ Tahsin Gürpınar, ${ }^{4}$ Serdar Demiröz ${ }^{1}$ \\ Department of Orthopedics and Traumatology, ${ }^{1}$ Medical Park Gebze Hospital, Kocaeli, Turkey \\ Department of OrthopedicsandTraumatology, ${ }^{2}$ University of Kyrenia, Kyrenia, Turkish Republic of Northern Cyprus \\ Department of Orthopedics and Traumatology, Baltalimanı Bone and Joint Diseases Training and Research Hospital, Istanbul, Turkey \\ Department of Orthopedics and Traumatology, ${ }^{4}$ Istanbul Training and Research Hospital, Istanbul, Turkey
}

Objective : It can be assumed that the progression of scoliosis in the juvenile period will increase the asymmetry in the rib cage, and thus will contribute to an increase in the breast asymmetry (BA) in the future. We are looking for answers to the questions; "How will the breasts look with respect to each other and what is the possibility of developing BA in the early follow-up period following the early surgical treatment and final fusion surgery of juvenile idiopathic scoliosis (JIS)?" For this reason, in this study, we aimed to evaluate the breast asymmetries of patients in the period after the final fusion.

Methods : Following growing rod treatment, final fusion was achieved in 12 females with JIS. We used the anthropomorphic measurement of the modified BREAST-V formula to assess whether there was an asymmetry between the breasts after an average of 4.8 years (2-11) following final fusion.

Results : In comparison, the mean volume of the left breast (222.4 $\mathrm{mL}$ [range, 104.1-330.2]) was larger than the mean volume of the right breast volume ( $214.5 \mathrm{~mL}$ [range, $95.2-326.7]$ ) ( $p=0.034)$. The left breast was larger in $75 \%$ of the patients. BA was observed in $50 \%$ of the patients. No correlation was detected between the Cobb angle of the patient after final fusion and BA ( $p=0.688)$.

Conclusion : In the late follow-up period, BA was detected in $50 \%$ of the patients with JIS who achieved final fusion after treatment with growing rod. In majority of the patients, left breast was larger. The patients with JIS and their families can be informed prior to the operation about the probability of BA seen in the follow-up period after fusion.

Key Words : Spine · Growing rod · Breast · Scoliosis · Surgery.

\section{INTRODUCTION}

Scoliosis is a 3-dimensional torsional deformity of the spine $e^{14,15,17,27)}$, and is frequently seen with unilateral protrusion of the ribs on our back especially in the scoliosis of the thoracic region ${ }^{7,18,26)}$. Both in historical and modern-day treatments, correction of the clinical scoliotic deformity in early-onset scoliosis (EOS) has been the main focus of posterior interven-

- Received : September 19, 2019 •Accepted : November 9, 2019

- Address for reprints : Barış Polat

Department of Orthopedics and Traumatology, University of Kyrenia, Șehit Yahya Bakır Sokak, Karakum, Kyrenia 99320, Turkish Republic of Northern Cyprus Tel : +90 533844 47 55, Fax : +90 392815 99 98, E-mail : drbpolat@hotmail.com, ORCID : https://orcid.org/0000-0001-8229-6412

This is an Open Access article distributed under the terms of the Creative Commons Attribution Non-Commercial License (http://creativecommons.org/licenses/by-nc/4.0) which permits unrestricted non-commercial use, distribution, and reproduction in any medium, provided the original work is properly cited. 
tion, in deformity correction during spinal fusion after treatment with growing rod for EOS. The thoracic curve is successfully treated with final fusion performed with posterior pedicle screw instrumentation following the treatment of EOS with growing rod. Previously, the spine surgeons had concentrated only on the posterior deformity, rather than the deformity of the anterior chest wall ${ }^{1,2,533,35)}$. However, when scoliosis patients look in the mirror, they can face cosmetic problems as they encounter asymmetry in the breast and anterior wall of the chest. Recently, in addition to the cosmetic appearance of the back of the body in scoliosis, the appearance of the front of our body has begun to gain importance. Many studies have focused on objectively demonstrating the presence of breast and chest wall asymmetry in scoliosis patients ${ }^{8-10,22,24,28,29,31,34)}$. Shape of the anterior chest wall is highly variable in scoliosis patients with similar Cobb angles. Correction of the thoracic scoliosis after surgical treatment may lead to anterior chest wall deformity, but in some cases the deformity may continue unchanged, or the existing protrusion may increase and worsen. Although the protrusion on the anterior costal projection on concavity does not lead to an important complaint like the rib hump on the back; this unpleasant anterior costal projection leads to cosmetic chest wall deformity which distorts the appearance of the body and causes a cosmetic concern in patients by contributing to breast asymmetry $(\mathrm{BA})^{211}$.

The positive or negative effects of prevention of the deformity progression with early treatment both on the differential changes of the anterior chest wall and on the breast mass in the late follow-up period can be an issue of concern for juvenile idiopathic scoliosis (JIS) patients.

Since the effect of managing the deformity on breast development and BA is not known in patients with scoliosis operated with the growing rod technique, in this study, we aimed to evaluate the possibility of developing BA and the condition of the breasts with respect to each other in the long follow-up period following the prevention of the scoliosis progression in JIS patients treated with the growing rod method.

\section{MATERIALS AND METHODS}

The study was approved in advance by the Institutional Review Board (RY-2019-18) and all patients signed an informed consent form. Growing rod technique was used in 12 female

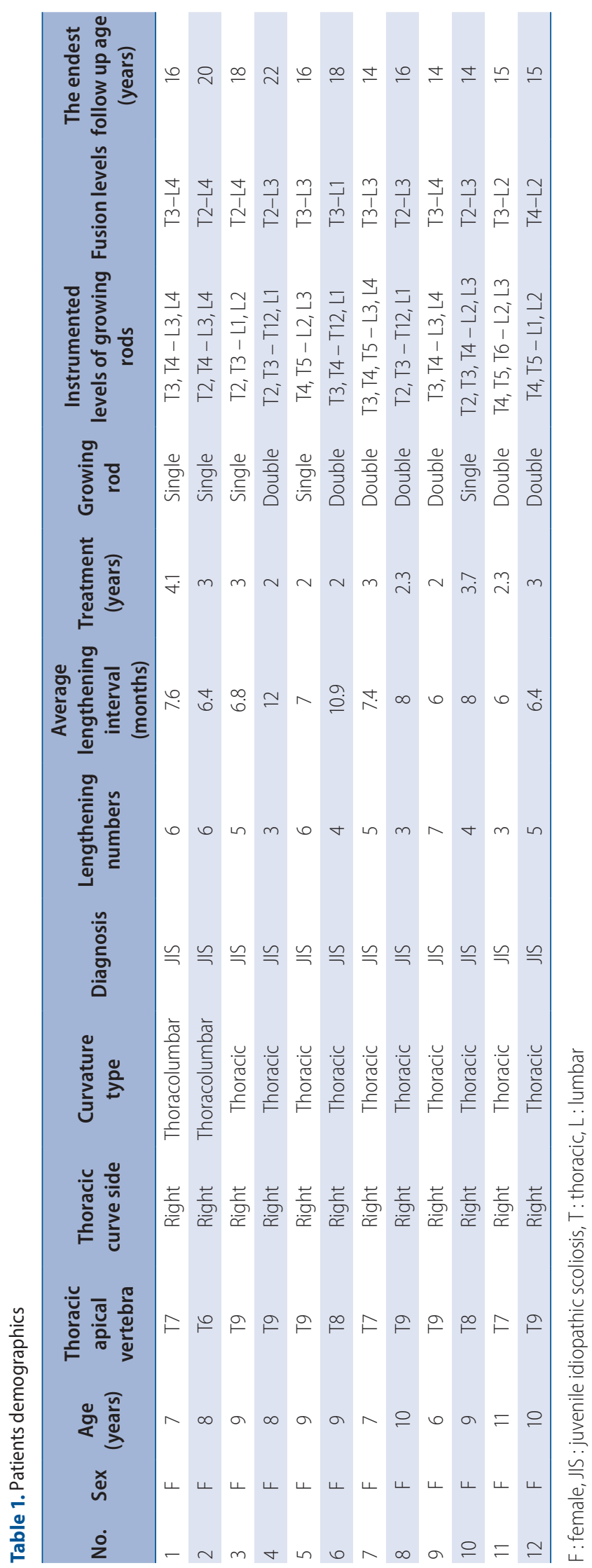


patients with EOS due to juvenile idiopathic etiologies, between the years 2007 and 2012 in institution. Criteria for inclusion in the study, respectively : 1) girl patients with right JIS, 2) final fusion patients, 3) patients with structural thoracic curve, 4) tanner stages of breasts : 4 and $>4,5$ ) photographied patients with body erect, arms on the side at follow up period after final fusion, 6) no additional malfarmation on the anterior chest wall (such as pectus excavatum and pectus carinatum), 7) no operation relation to the anterior chest wall and BA, and 8) patients with risser sign 4 and 5 and $>2$ years postmenarche. The following exclusion criteria were applied : 1) patients with a history of augmentation mammaplasty or any other breast surgery. Clinical results are presented in Table 1. Mean age was 8.6 years (range, 6-11) preoperatively. The mean followup age after final fusion was 16.5 years (range, 14-22). The mean follow-up period after the final fusion was 4.8 years (range, 2-11). Dual growing rod technique was performed in eight patients and single growing rod technique was performed in four patients. The mean number of lengthening was 4.8 (range, 3-7). Twelve patients were followed until definitive surgery, and finally treated with posterior segmental instrumentation and fusion.

In anteroposterior radiographies, major curve Cobb angle was measured preoperatively, early postoperatively and during the last follow-up after final fusion (Fig. 1).

In order to perform morphological measurements of the breast in the follow-up period after final fusion, anterior, posterior and lateral photographs of the patients were taken in erect position and with their arms on the side and clothing off. A total of three morphological parameters were employed for the estimation of breast profile and symmetry by selecting a number of anthropological points. The measured parameters were the following : sternal notch-nipple distance (SN-N), breast projection (BP), and nipple-inframammary fold distance (N-IMF) (Fig. 2). Breast volume (BV) was calculated using the modified BREAST-V formula : $\mathrm{BV}=-231.66+0.5747$
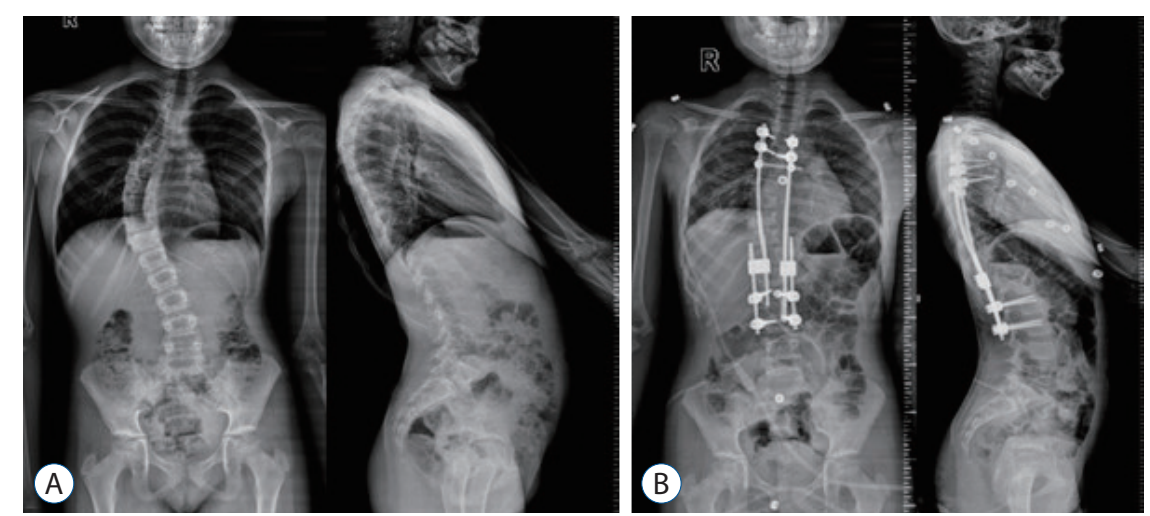

Fig. 1. A : Preoperative anteroposterior and lateral radiography. B : Early postoperative anteroposterior and lateral radiography (patient No. 12).

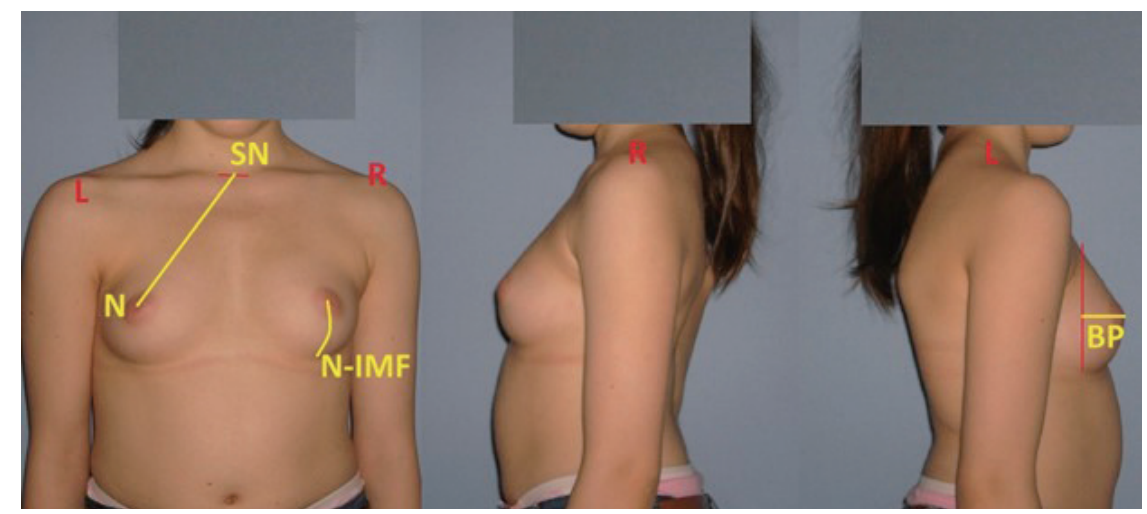

Fig. 2. Three morphological parameters on breasts profile : 1) sternal notch-nipple distance (SN-N); 2) nipple-inframammary fold distance (N-IMF); and 3) breast projection (BP) (patient No. 12). 
Breast Asymmetry in Scoliosis | Atici Y, et al.

Table 2. Coronal and sagittal radiological parameters result

\begin{tabular}{|c|c|c|c|c|c|}
\hline & Min-max & Median & Mean \pm SD & $p$-vlaue* & $p$-value ${ }^{\dagger}$ \\
\hline \multicolumn{6}{|c|}{ Cervical lordosis (C2-C7) } \\
\hline Preoperative & $10-44$ & 28.5 & $26.5 \pm 12.5$ & & \\
\hline Postoperative & $7-43$ & 25.0 & $22.5 \pm 12.1$ & $0.414^{\ddagger}$ & \\
\hline Last follow-up & $3-59$ & 16.0 & $21.7 \pm 18.4$ & $0.271^{\ddagger}$ & $0.480^{\ddagger}$ \\
\hline \multicolumn{6}{|c|}{ Thoracic kyphosis (T1-T12) } \\
\hline Preoperative & $33-72$ & 48.0 & $50.8 \pm 12.7$ & & \\
\hline Postoperative & $23-59$ & 40.0 & $40.9 \pm 11.0$ & $0.014^{\ddagger}$ & \\
\hline Last follow-up & $21-55$ & 38.0 & $37.4 \pm 11.9$ & $0.021^{\ddagger}$ & $0.182^{\ddagger}$ \\
\hline \multicolumn{6}{|c|}{ Lumbar lordosis (L1-S1) } \\
\hline Preoperative & $35-67$ & 46.5 & $50.3 \pm 11.4$ & & \\
\hline Postoperative & $29-64$ & 47.0 & $45.1 \pm 12.0$ & $0.530^{\ddagger}$ & \\
\hline Last follow-up & $23-62$ & 46.0 & $44.0 \pm 10.8$ & $0.230^{\ddagger}$ & $1.000^{\ddagger}$ \\
\hline \multicolumn{6}{|l|}{ Pelvic tilt } \\
\hline Preoperative & $-4-23$ & 4.0 & $5.9 \pm 8.2$ & & \\
\hline Postoperative & $-7-29$ & 7.0 & $7.3 \pm 9.3$ & $0.624^{\ddagger}$ & \\
\hline Last follow-up & $0-23$ & 6.5 & $7.9 \pm 7.9$ & $0.221^{\ddagger}$ & $0.919^{\ddagger}$ \\
\hline \multicolumn{6}{|l|}{ Sacral slope } \\
\hline Preoperative & $21-50$ & 40.5 & $39.5 \pm 10.1$ & & \\
\hline Postoperative & $24-49$ & 39.0 & $37.5 \pm 8.0$ & $0.263^{\ddagger}$ & \\
\hline Last follow-up & $19-74$ & 36.5 & $36.9 \pm 14.3$ & $0.386^{\ddagger}$ & $0.959^{\ddagger}$ \\
\hline \multicolumn{6}{|l|}{ Pelvic incidance } \\
\hline Preoperative & $28-67$ & 46.0 & $45.7 \pm 12.4$ & & \\
\hline Postoperative & $28-69$ & 43.5 & $45.2 \pm 12.2$ & $0.799^{\ddagger}$ & \\
\hline Last follow-up & $28-74$ & 41.5 & $45.1 \pm 14.5$ & $0.937^{\ddagger}$ & $0.799^{\ddagger}$ \\
\hline \multicolumn{6}{|c|}{ Torakal scoliosis Cobb angle } \\
\hline Preoperative & $28-72$ & 51.0 & $52.7 \pm 13.4$ & & \\
\hline Postoperative & $7-56$ & 31.0 & $31.4 \pm 14.4$ & $0.002^{\ddagger}$ & \\
\hline Last follow-up & $7-52$ & 26.5 & $27.7 \pm 12.0$ & $0.002^{\ddagger}$ & $0.476^{\ddagger}$ \\
\hline \multicolumn{6}{|c|}{ Sagittal balance $(\mathrm{cm})$} \\
\hline Preoperative & $-7-4$ & -1.2 & $-0.7 \pm 3.5$ & & \\
\hline Postoperative & $-7-6$ & -1.9 & $-1.3 \pm 3.5$ & $0.505^{\ddagger}$ & \\
\hline Last follow-up & $-7-3$ & -3.0 & $-2.4 \pm 3.0$ & $0.084^{\ddagger}$ & $0.755^{\ddagger}$ \\
\hline \multicolumn{6}{|c|}{ Coronal balance (cm) } \\
\hline Preoperative & $0-4$ & 1.2 & $1.4 \pm 1.2$ & & \\
\hline Postoperative & $0-3$ & 1.0 & $1.1 \pm 0.7$ & $0.270^{\ddagger}$ & \\
\hline Last follow-up & $0-2$ & 0.5 & $0.7 \pm 0.7$ & $0.116^{\ddagger}$ & $0.259^{\ddagger}$ \\
\hline \multicolumn{6}{|l|}{ T1-S1 distance $(\mathrm{cm})$} \\
\hline Preoperative & $27-36$ & 30.9 & $31.1 \pm 2.4$ & & \\
\hline Postoperative & $30-37$ & 33.2 & $33.4 \pm 2.3$ & $0.002^{\ddagger}$ & \\
\hline Last follow-up & $31-40$ & 36.3 & $35.9 \pm 3.2$ & $0.002^{\ddagger}$ & $0.002^{\ddagger}$ \\
\hline
\end{tabular}

${ }^{*}$ Compared with preop period. ${ }^{\dagger}$ Compared with postop period. ${ }^{~}$ Wilcoxon test. SD : standard deviation, C : cervical, T: thoracic, L : lumbar, S : sacral 
$\times(\mathrm{SN}-\mathrm{N})^{2}+18.5478 \times \mathrm{BP}+14.5087 \times(\mathrm{N}-\mathrm{IMF})^{16)}$. A difference of over or below $5 \%$ between the volumes of two breasts were considered as BA.

\section{Statistical analysis}

SPSS version 15.0 for Windows (SPSS Inc., Chicago, IL, USA) was used for statistical analysis. Descriptive statistics; number and percentage were used for categorical variables; mean and standard deviation were used for numerical variables. Mann-Whitney U test were used for comparison of two groups for variables without normal distribution. The rate of the categorical variables among the groups was tested by the Fisher's exact test. The Wilcoxon signed-rank test were used for comparision of two related samples without normal distribution. Statistical significance level of alpha was accepted as $p<0.05$.

\section{RESULTS}

The data of patients are presented in Tables 1 and 2. Mean age was 8.6 years (range, 6-11) preoperatively. The mean endest follow-up age was 16.5 years (range, 14-22). The mean treatment time was 3 years (range, 2-4.1). The mean lengthe- ning number was 4.8 (range, 3-7). The mean lengthening interval was 7.7 months (range, 6-12).

The mean preoperative major curve Cobb angle, which was $51^{\circ}$ (range, $28^{\circ}-72^{\circ}$ ) improved to $31^{\circ}$ (range, $7^{\circ}-56^{\circ}$ ) in the initial postoperative period $(p<0.05)$. In the follow-up period, it was measured as $26.5^{\circ}$ (range, $\left.7^{\circ}-52^{\circ}\right)(p<0.05)$.

The follow up after final fusion, average morphological breast parameters are summarized in Table 3. The mean left BV (222.4 $\mathrm{mL}$ [range, 104.1-330.2]) was larger than the mean right breast volume (214.5 mL [range, 95.2-326.7]) $(p=0.034)$. No association was detected between the Cobb angle of the thoracic scoliosis patient in the preoperative, postoperative baseline and the late follow-up period after final fusion and BA $(p=0.092$, $p=0.873, p=0.688$ ).

In right thoracic scoliosis, $\mathrm{BA}$ (5\% or more in percentage) was present in six of the 12 patients (50\%). The left breast was larger in nine of the 12 patients (75\%).

BA was present in two of the six patients (33.3\%) with a preoperative thoracic scoliosis Cobb angle of $>50^{\circ}$ and four of the six patients $(66.7 \%)$ with a Cobb angle of $<50^{\circ}(p>0.05)$.

$\mathrm{BA}$ was present in three of the six patients $(50 \%)$ with a thoracic scoliosis Cobb angle of $>25^{\circ}$ in the late follow-up period after fusion and three of the six patients (50\%) with a Cobb angle of $<25^{\circ}(p>0.05)$. No statistically significant difference

Table 3. Scoliosis and breast measurements of patients

\begin{tabular}{|c|c|c|c|c|c|c|c|c|c|c|c|c|}
\hline \multirow[b]{2}{*}{ No. } & \multirow[b]{2}{*}{$\begin{array}{l}\text { The mean } \\
\text { preoperative } \\
\text { major curve } \\
\text { Cobb angle } \\
\left({ }^{\circ}\right)\end{array}$} & \multirow{2}{*}{$\begin{array}{l}\text { The mean } \\
\text { initial } \\
\text { postoperative } \\
\text { period major } \\
\text { curve Cobb } \\
\text { angle }\left(^{\circ}\right)\end{array}$} & \multirow{2}{*}{$\begin{array}{l}\text { The mean } \\
\text { follow-up } \\
\text { period major } \\
\text { curve Cobb } \\
\text { angle }\left(^{\circ}\right)\end{array}$} & \multicolumn{9}{|c|}{ Breast morphological parameters (endest follow-up period) } \\
\hline & & & & $\begin{array}{l}\text { Left SN-N } \\
\quad(\mathrm{mm})\end{array}$ & $\begin{array}{c}\text { Left BP } \\
(\mathrm{mm})\end{array}$ & $\begin{array}{l}\text { Left } \\
\text { N-IMF } \\
(\mathrm{mm})\end{array}$ & $\begin{array}{c}\text { Left } \\
\text { breast } \\
\text { volume } \\
\text { (mL) }\end{array}$ & $\begin{array}{l}\text { Right } \\
\text { SN-N } \\
(\mathrm{mm})\end{array}$ & $\begin{array}{l}\text { Right } \\
\text { BP } \\
(\mathrm{mm})\end{array}$ & $\begin{array}{l}\text { Right } \\
\text { N-IMF } \\
(\mathrm{mm})\end{array}$ & $\begin{array}{l}\text { Right } \\
\text { breast } \\
\text { volume } \\
\text { (mL) }\end{array}$ & $\begin{array}{c}\text { Breast } \\
\text { asymmetry }\end{array}$ \\
\hline 1 & 45 & 30 & 17 & 233 & 71 & 82 & 330.2 & 234 & 68 & 81 & 326.7 & No \\
\hline 2 & 70 & 56 & 25 & 214 & 90 & 78 & 311.6 & 217 & 90 & 74 & 313.2 & No \\
\hline 3 & 62 & 32 & 40 & 228 & 49 & 86 & 282.4 & 227 & 50 & 83 & 277.6 & No \\
\hline 4 & 65 & 35 & 28 & 200 & 66 & 91 & 252.7 & 196 & 61 & 86 & 227 & Yes \\
\hline 5 & 59 & 24 & 33 & 195 & 63 & 67 & 200.9 & 186 & 65 & 72 & 192.2 & No \\
\hline 6 & 28 & 12 & 25 & 214 & 45 & 84 & 222.3 & 196 & 47 & 88 & 204 & Yes \\
\hline 7 & 40 & 23 & 15 & 187 & 49 & 42 & 121.1 & 190 & 47 & 47 & 131.2 & Yes \\
\hline 8 & 48 & 7 & 7 & 201 & 49 & 77 & 203.1 & 207 & 47 & 73 & 207.7 & No \\
\hline 9 & 54 & 49 & 36.6 & 180 & 47 & 43 & 104.1 & 180 & 46 & 41 & 95.2 & Yes \\
\hline 10 & 41 & 34 & 30 & 201 & 49 & 53 & 168.4 & 198 & 44 & 48 & 144.9 & Yes \\
\hline 11 & 72 & 47 & 52 & 223 & 71 & 60 & 272.9 & 225 & 67 & 58 & 267.7 & No \\
\hline 12 & 48 & 28 & 24 & 201 & 52 & 70 & 198.5 & 199 & 51 & 66 & 186.3 & Yes \\
\hline
\end{tabular}

SN-N : sternal notch-nipple distance, BP : breast projection, N-IMF : nipple-inframammary fold distance 
was detected between the BVs of the right and left breasts with a thoracic scoliosis Cobb angle of $>25^{\circ}$ or $<25^{\circ}$ in the late follow-up period after fusion $(p>0.05)$.

The thoracic apical vertebra was the T6 vertebra in one patient (8.3\%), T8 in two patients (16.7\%), T7 in three patients (25.0\%) and T9 in six patients (50\%). There was no statistically significant difference regarding BA between the patients whose thoracic apical vertebra was the T9 vertebra versus those with a thoracic apical vertebra above T9 $(p>0.05)$.

\section{DISCUSSION}

Breast is a very difficult organ to measure due to its various sizes, contours, width, length, depth, projection, nipple level and volume. In evaluation of the BA, parameters such as breast mound volume, inframammary fold position, nippleareola complex size and position, scoliosis, pectus excavatum/ carinatum, rib aring and kyphosis/lordosis are affected and makes the evaluation complex ${ }^{30)}$. Various methods have been used to measure breast volume.

There are different methods of measuring the breast volume such as three-dimensional (3D) laser scans, nuclear magnetic resonance imaging (MRI), computed tomography (CT), thermoplastic casting and anthropomorphic methods ${ }^{4,16,19,20,32)}$. Although 3D modelling and MRI measuring methods are more reliable in comparison to mathematical modelling methods, unfortunately, 3D laser scan, CT, and MRI are too costly for routine assessments. Thus, anthropomorphic method is suggested as a simple way of evaluating and estimating breast volume ${ }^{4)}$. The ideal measurement technique should be comfortable for the patient, radiation-free, non-invasive and low-cost, and most reliable close to reality ${ }^{9,20)}$. The closest one to this purpose was the anthropomorphic measurement technique using photographs, and we preferred this technique in evaluating our cases.

$\mathrm{BA}$ is defined as the difference in the shape, position or the volume of the breast or nipple (nipple-areola complex) complex. Following the curve progression of the spine at early ages, the axial plane and the rib cage also undergo torsion and gains a structural deformity; and an asymmetrical contour develops on the anterior wall surface of the rib cage at advanced age $e^{6,13,15,23,31)}$. Increased asymmetry in the thoracic cavity, seen concurrently with the progression of the deformity in scoliosis patients, causes an increase in the size of the breasts as well as a change in their position ${ }^{9,15,17,24,31)}$. In right thoracic scoliosis patients, a protrusion of the rib is seen on the anterior surface of the chest wall, on the concave side ${ }^{24)}$. This developmental phase is accompanied by the bilateral development of mammary glands. Spontaneous bilateral BA is widely observed $^{22}$. The left breast is located more caudally and is larger in female adolescents with right thoracic idiopathic scolio$\operatorname{sis}^{28,34)}$. In Shi et al.'s study ${ }^{31)}$, the incidence of BA in surgically treated female right thoracic idiopathic scoliosis is notable, with the concave breast being larger, more extroversive, and more concentrated than the convex breast. In our study, we established that left breast was larger in $75 \%$ of the patients.

In the beginning, the coronal spinal curvature is more prominent in the posterior part of the scoliosis ${ }^{35)}$; whereas in later stages the posterior spinal sagittal plane begins to gain importance ${ }^{2,3)}$. Ignorance of the anterior side of the rib cage leads to postoperative cosmetic failure, physiological distress and increased asymmetry of the breast. For this reason, attention is now focused on the BA in scoliosis patients ${ }^{11,12,21,22,25,28,31,34)}$. It can be necessary to inform and evaluate the scoliosis patients both posteriorly and anteriorly. Scoliosis patients and their families can be informed about the possibility of having a BA before and after surgery.

Ramsay et al. ${ }^{28)}$ reported a weak positive correlation between the BA and Cobb angle in girl patients with idiopathic scoliosis but also stated that the difference was statistically insignificant. The authors also found no statistically significant correlation between BA and thoracic rib hump. Similarly, in the study of Shi et al. ${ }^{31)}$, it was reported that there was no statistically significant difference between the BA and the Cobb angle. In another study, Tsai et al. ${ }^{34)}$ found that the severity of scoliosis showed significant correlation with the breast volume asymmetry differences. The authors discovered that, when untreated, each degree in the Cobb angle created a volume difference of approximately $3 \mathrm{~mL}$ in scoliotic children. The authors determined that the imbalance on the shoulder and posture, together with scoliosis, caused asymmetrical differences in the inframammary fold level ${ }^{34)}$. It was shown that the prevalence of psychopathology in patients with scoliosis was significantly increased in comparison of those with a Cobb angle above 10 degrees with the normal population ${ }^{7}$. In Duri et al.'s study ${ }^{10)}$, BA was correlated with the preoperative curve size. In our study, we could not establish a statistically signifi- 
cant relationship between the Cobb angle and BA measured in the preoperative period and the late follow-up period after final fusion $(p>0.05)$. Obviously, these results may be due to the small number of our patients.

Regardless of the amount of curve correction achieved and the surgical technique, the improvement in the BA perception of the patients developed positively in the postoperative two years after spinal fusion. The authors suggested that this finding was important in enlightening the patients and their families about what could happen in the future ${ }^{10)}$. In our study, while the mean follow-up period after the final fusion was 4.8 years (2-11), 50\% of our patients had BA.

This study is the first study focusing on evaluating the BA after growing rod treatment of JIS. As for the limitations of the study; first, we could not prospectively evaluate the changes in BA of the patients since we did not have their unclothed photos before initial surgery, after initial surgery and before fusion. As a result, it was not possible to evaluate whether the $\mathrm{BA}$ and the breast mass gave an adaptive remodeling response to the changes in the rib cage with intermittent extensions. We used a less reliable method than other methods as the measurements were performed using photographs. The absence of a control group and the small number of patients were the other limitations of our study. It can be concluded that further randomized, controlled trials with high methodological quality and large number of patients are required to evaluate efficacy of growing rod application on BA of patients with JIS.

The BA seen in $50 \%$ of the EOS patients in the late period after the final fusion points out to the need that the patients and their family can be advised about this issue.

\section{CONCLUSION}

BA was detected in $50 \%$ of the patients with JIS after end of treatment with growing rod. In $75 \%$ of the patients, left breast was larger. JIS patients and their families can be informed about the possibility of having a BA after end of treatment with growing rod.

\section{CONFLICTS OF INTEREST}

No potential conflict of interest relevant to this article was reported.

\section{INFORMED CONSENT}

Informed consent was obtained from all individual participants included in this study

\section{AUTHOR CONTRIBUTIONS}

\author{
Conceptualization : YA \\ Data curation : TG \\ Formal analysis : SE \\ Funding acquisition : SD \\ Methodology : SE \\ Project administration : TG \\ Visualization : BP, TG \\ Writing - original draft : $Y A, S D$ \\ Writing - review \& editing : BP, SD
}

\section{ORCID}
Yunus Atici
https://orcid.org/0000-0002-9661-4618
Barış Polat
https://orcid.org/0000-0001-8229-6412
Sinan Erdogan
https://orcid.org/0000-0002-8517-3925
Tahsin Gürpınar
https://orcid.org/0000-0002-8194-6492
Serdar Demiröz
https://orcid.org/0000-0002-2403-3750

\section{- Acknowledgements}

This study conducted in fourth affiliation.

\section{References}

1. Akbarnia BA, Marks DS, Boachie-Adjei O, Thompson AG, Asher MA : Dual growing rod technique for the treatment of progressive early-onset scoliosis: a multicenter study. Spine (Phila Pa 1976) 30(17 Suppl) : S46-S57, 2005

2. Atici Y, Akman YE, Erdogan S, Sari S, Yavuz U, Carkci E, et al. : The ef- 
fect of growing rod lengthening technique on the sagittal spinal and the spinopelvic parameters. Eur Spine J 24 : 1148-1157, 2015

3. Bekmez S, Demirkiran HG, Dede O, Atici Y, Balioglu MB, Kruyt M, et al. : Spinal instrumentation in growing children retards the natural development of pelvic incidence. J Pediatr Orthop 39 : 141-145, 2019

4. Bulstrode N, Bellamy E, Shrotria S: Breast volume assessment: comparing five different techniques. Breast 10 : 117-123, 2001

5. Caniklioglu M, Gokce A, Ozturkmen Y, Gokay NS, Atici Y, Uzumcugil O : Clinical and radiological outcome of the growing rod technique in the management of scoliosis in young children. Acta Orthop Traumatol Turc 46 : 379-384, 2012

6. Chen SH, Huang TJ, Lee YY, Hsu RW : Pulmonary function after thoracoplasty in adolescent idiopathic scoliosis. Clin Orthop Relat Res 399 : 152-161, 2002

7. Cholewicki J, Crisco JJ 3rd, Oxland TR, Yamamoto I, Panjabi MM : Effects of posture and structure on three-dimensional coupled rotations in the lumbar spine. A biomechanical analysis. Spine (Phila Pa 1976) 21 : 2421-2428, 1996

8. Cruz NI, Korchin L : Breast asymmetry pattern in women with idiopathic scoliosis. Bol Asoc Med P R 105 : 9-12, 2013

9. Denoel C, Aguirre MF, Bianco G, Mahaudens PH, Vanwijck R, Garson S, et al. : Idiopathic scoliosis and breast asymmetry. J Plast Reconstruct Aesthet Surg 62 : 1303-1308, 2009

10. Duri R, Brown K, Johnson M, McIntosh A : Patients' perceptions of breast asymmetry improve after spinal fusion for adolescent idiopathic scoliosis. Spine Deform 7 : 80-83, 2019

11. Eidlitz-Markus T, Mukamel M, Haimi-Cohen Y, Amir J, Zeharia A : Breast asymmetry during adolescence: physiologic and non-physiologic causes. Isr Med Assoc J 12 : 203-206, 2010

12. Gabriel A, Fritzsche S, Creasman C, Baqai W, Mordaunt D, Maxwell GP : Incidence of breast and chest wall asymmetries: 4D photography. Aesthet Surg J 31 : 506-510, 2011

13. Harvey CJ Jr, Betz RR, Clements DH, Huss GK, Clancy M : Are there indications for partial rib resection in patients with adolescent idiopathic scoliosis treated with Cotrel-Dubousset instrumentation? Spine (Phila Pa 1976) 18 : 1593-1598, 1993

14. Hayashi K, Upasani VV, Pawelek JB, Aubin CE, Labelle H, Lenke LG, et al. : Three-dimensional analysis of thoracic apical sagittal alignment in adolescent idiopathic scoliosis. Spine (Phila Pa 1976) 34 : 792-797, 2009

15. Hong JY, Suh SW, Easwar TR, Modi HN, Yang JH, Park JH : Evaluation of the three-dimensional deformities in scoliosis surgery with computed tomography: efficacy and relationship with clinical outcomes. Spine (Phila Pa 1976) 36 : E1259-E1265, 2011

16. Huang NS, Quan CL, Mo M, Chen JJ, Yang BL, Huang XY, et al. : A prospective study of breast anthropomorphic measurements, volume and ptosis in 605 Asian patients with breast cancer or benign breast disease. PLoS One 12 : e0172122, 2017

17. Illés $T$, Tunyogi-Csapó $M$, Somoskeöy $S$ : Breakthrough in three-dimensional scoliosis diagnosis: significance of horizontal plane view and vertebra vectors. Eur Spine J 20 : 135-143, 2011
18. Jefferson RJ, Weisz I, Turner-Smith AR, Harris JD, Houghton GR : Scoliosis surgery and its effect on back shape. J Bone Joint Surg Br 70 : 261-266, 1988

19. Kovacs L, Eder M, Hollweck R, Zimmermann A, Settles M, Schneider A, et al. : Comparison between breast volume measurement using 3D surface imaging and classical techniques. Breast 16 : 137-145, 2007

20. Longo B, Farcomeni A, Ferri G, Campanale A, Sorotos M, Santanelli F : The BREAST-V: a unifying predictive formula for volume assessment in small, medium and large breasts. Plast Reconstr Surg 132 : 1e-7e, 2013

21. Mao SH, Qiu Y, Zhu ZZ, Zhu F, Liu Z, Wang B : Clinical evaluation of the anterior chest wall deformity in thoracic adolescent idiopathic scoliosis. Spine (Phila Pa 1976) 37 : E540-E548, 2012

22. Mao SH, Shi B, Sun X, Liu Z, Zhu ZZ, Qian BP, et al. : Morphometric analysis of iatrogenic breast asymmetry secondary to operative breast shape changes in thoracic adolescent idiopathic scoliosis. Eur Spine J 25 : 3075-3081, 2016

23. Min K, Waelchli B, Hahn F : Primary thoracoplasty and pedicle screw instrumentation in thoracic idiopathic scoliosis. Eur Spine J 14 : 777 782, 2005

24. Normelli H, Sevastik JA, Ljung G, Jönsson-Söderström AM : The symmetry of the breasts in normal and scoliotic girls. Spine (Phila Pa 1976) $11: 749-752,1986$

25. Oh CH, Shim YS, Yoon SH, Park HC, Park CO, Lee MS : The psychopathological influence of adolescent idiopathic scoliosis in korean male : an analysis of multiphasic personal inventory test results. J Korean Neurosurg Soc 53 : 13-18, 2013

26. Perdriolle R, Vidal J : Morphology of scoliosis: three-dimensional evolution. Orthopedics $10: 909-915,1987$

27. Poncet $\mathrm{P}$, Dansereau J, Labelle H : Geometric torsion in idiopathic scoliosis: three-dimensional analysis and proposal for a new classification. Spine (Phila Pa 1976) 26 : 2235-2243, 2001

28. Ramsay J, Joncas J, Gilbert G, Trop I, Cheriet F, Labelle H, et al. : Is breast asymmetry present in girls with adolescent idiopathic scoliosis? Spine Deform 2 : 374-379, 2014

29. Ramsay J, Seoud L, Barchi S, Cheriet F, Joncas J, Turgeon I, et al. : Assessment of breast asymmetry in adolescent idiopathic scoliosis using an automated 3D body surface measurement technique. Spine Deform 5 : 152-158, 2017

30. Rohrich RJ, Hartley W, Brown S : Incidence of breast and chest wall asymmetry in breast augmentation: a retrospective analysis of 100 patients. Plast Reconstr Surg 111 : 1513-1519; discussion 1520-1523, 2003

31. Shi B, Mao S, Sun X, Xu L, Zhu Z, et al. : Both bilateral breast volume discrepancy and asymmetric anterior chest wall shape contribute to the unsightly breast contour in female right thoracic idiopathic scoliosis. Clin Spine Surg 30 : E344-E350, 2017

32. Sigurdson LJ, Kirkland SA : Breast volume determination in breast hypertrophy: an accurate method using two anthropomorphic measurements. Plast Reconstr Surg 118 : 313-320, 2006

33. Thompson GH, Akbarnia BA, Kostial P, Poe-Kochert C, Armstrong DG, 
Roh J, et al. : Comparison of single and dual growing rod techniques followed through definitive surgery: a preliminary study. Spine (Phila Pa 1976) $30:$ :2039-2044, 2005

34. Tsai FC, Hsieh MS, Liao CK, Wu ST : Correlation between scoliosis and breast asymmetries in women undergoing augmentation mammaplasty.
Aesth Plast 34 : 374-380, 2010

35. Uzümcügil O, Atici Y, Ozturkmen Y, Yalcinkaya M, Caniklioglu M : Evaluation of shoulder balance through growing rod intervention for earlyonset scoliosis. J Spinal Disord Tech 25 : 391-400, 2012 